Electrochemical oxidation of ordered mesoporous carbons and the

\title{
influence of graphitization
}

Sara Pérez-Rodríguez*, David Sebastián, María J. Lázaro*

${ }^{1}$ Instituto de Carboquímica (CSIC), Miguel Luesma Castán 4, 50018, Zaragoza, España.

*Corresponding author: mlazaro@icb.csic.es, sperez@icb.csic.es 


\begin{abstract}
Ordered mesoporous carbon materials (OMC) obtained by the template carbonization pathway from silica templates (sacrificial method) exhibit promising features for many applications mainly due to their large surface area. Graphitization is a common approach to improve the electrical conductivity and degradation resistance. We have investigated the graphitization of two different $\mathrm{OMC}$ at $1500^{\circ} \mathrm{C}$ and the electrochemical oxidation by potential holding at $1.4 \mathrm{~V}$ vs. reversible hydrogen electrode (RHE) in acidic electrolyte. Graphitization conducts to a significant reduction of the electrooxidation associated charge, between 50 and $90 \%$ depending on the carbon properties, together with a decrease of surface area of $35-48 \%$. The materials still exhibit a large electrochemical surface area, according to electrochemical impedance and cyclic voltammetry experiments. Upon electrooxidation, the relative amount of oxygen increases according to a comparative analysis of X-ray photoelectron spectroscopy test of the electrodes before and after potential holding. The results are of interest to define strategies towards the amelioration of carbon degradation by electrooxidation in electrochemical devices.
\end{abstract}

Keywords: ordered mesoporous carbon, carbon electrooxidation, graphitization, degradation. 


\section{Introduction}

Ordered mesoporous carbon (OMC) materials obtained by the template carbonization pathway from silica templates (hard-templating or sacrificial methodology) exhibit tunable nanostructures and developed mesoporosity with widely open interconnected pores, making them promising materials for many applications, such as sensors and biosensors [1], electrochemistry [2], adsorption and catalysis [3], or electrochemical energy storage [4-7] and conversion [8,9]. Among them, OMC have attracted special attention for their application at the catalytic layers of low temperature fuel cells (e.g. polymer electrolyte membrane fuel cells, PEMFC and direct alcohol fuel cells, DAFC). Their large surface area and ordered structure facilitate the dispersion of the active phase for OMC-supported Pt-based nanoparticles, thus favoring the performance of these electrochemical devices [10-18]. Open-frame porous carbons obtained by the sacrificial methodology from silica templates have also been recently investigated as a hosting structure for metal-nitrogen-carbon coordinates to be applied as platinum-free catalysts [19-26].

One drawback of OMC is their low electrical conductivity due to their amorphous character, and consequently high ohmic resistances can be found in electrochemical applications, leading to a decrease of the performance of the device (fuel cells, capacitors, etc.). Furthermore, carbon materials tend to undergo electrooxidation at highly positive potentials [27], which is considered to be one of the main problems facing the lifetime of positive electrodes in electrochemical devices. In order to address these limitations, different graphitization methodologies of templated mesoporous carbons have been proposed, such as heat treatments at high temperature [27-31] or catalytic approaches [32-34]. Catalytic approaches involve the use of metals (e.g. Fe or Ni), which need to be removed in a final step using oxidizing agents and increasing the cost of the final catalyst. 
Whereas, heat treatments at high temperature have been used to increase the graphitization degree of OMC supports and successfully deposit metal nanoparticles on the surface despite the decrease of the support oxygen content upon annealing $[27,35]$.

Carbon electrooxidation is a complex multi-step process involving both the formation of oxygen species and the complete oxidation to $\mathrm{CO}_{2}$ at elevated potentials through the reaction in equation 1 [36]:

$\mathrm{C}+2 \mathrm{H}_{2} \mathrm{O} \rightarrow \mathrm{CO}_{2}+4 \mathrm{H}^{+}+4 \mathrm{e}^{-} \quad\left(\mathrm{E}^{0}=0.207 \mathrm{~V}\right.$ vs. RHE $)$

Although many works have been devoted to study carbon electrooxidation using different nanostructured carbon materials [37-49], the exact mechanism is not completely clear. Additionally, the influence of OMC graphitization on carbon electrooxidation needs to be further studied.

In this work, two different OMC with adjustable textural and morphological properties have been synthesized and heat treated at $1500{ }^{\circ} \mathrm{C}$ to increase their crystallinity and their electrical conductivity. The influence of graphitization on the electrochemical oxidation of carbon was evaluated by potential holding at $1.4 \mathrm{~V}$ vs RHE in aqueous acid medium (0.5 $\left.\mathrm{M} \mathrm{H} \mathrm{H}_{2} \mathrm{SO}_{4}\right)$. Additionally, cyclic voltammetry and electrochemical impedance spectroscopy have been used to study the effect of heat treatment on the electrochemical behavior, together with chemical analysis to elucidate changes in the electrode composition.

\section{Experimental}

\subsection{Synthesis of ordered mesoporous carbons}

OMC were obtained from SBA-15 silica (template) following the hard-templating methodology using different mass ratio $(\mathrm{R})$ of the silica precursor (Tetraethyl Orthosilicate, TEOS, 98 wt. \%, Aldrich) and the surfactant (P123) (R = TEOS/P123). A furan resin/acetone mixture was used as carbon precursor. Further details can be found in 
[50]. Following this procedure, two different materials were obtained: OMC-R2 and OMC-R5, with $\mathrm{R}=2$ and 5, respectively. Previous works of our group showed that carbons with an open mesoporous structure and a high surface area are obtained using these mass ratio $\mathrm{R}$ values [13,50]. OMC were washed with $1.1 \mathrm{M} \mathrm{NaOH}$ (98 wt. \%, Panreac) water/ethanol (96\% v/v, Panreac) solution (with a volume ratio water/ethanol $=1: 0.3)$ in order to remove the silica templates.

As-synthesized $\mathrm{OMC}$ were subjected to a heat treatment at $1500^{\circ} \mathrm{C}$ for $1 \mathrm{~h}$ in a graphite electrical furnace (heating rate $10{ }^{\circ} \mathrm{C} \mathrm{min}^{-1}$ ) under $\mathrm{Ar}$ flow [27,51]. This temperature $\left(1500{ }^{\circ} \mathrm{C}\right)$ has been found to favor the development of a crystalline carbon framework without a significant impact on the mesoporous structure of OMC [27,31,51]. We will refer to this treatment as graphitization. Graphitized ordered mesoporous carbons (gOMC) will be labelled as gOMC-R2 and gOMC-R5.

\subsection{Physicochemical characterization}

Transmission electron microscope (TEM) micrographs of OMC and gOMC were acquired with a JEOL-2000 FXII microscope equipped with a LaB6 gun.

$\mathrm{X}$-ray diffraction (XRD) patterns of $\mathrm{OMC}$ and $\mathrm{gOMC}$ were recorded using a Bruker AXS D8 Advance diffractometer with a $\theta-\theta$ configuration and using $\mathrm{Cu} \mathrm{K} \alpha$ radiation $(\lambda=0.15406 \mathrm{~nm})$. Scans were recorded at $1^{\circ} \min ^{-1}$ for $2 \theta$ values from $10^{\circ}$ to $80^{\circ}$. Graphite crystallite sizes $\left(\mathrm{L}_{\mathrm{c}}\right)$ were calculated from Scherrer's equation on the $(002)$ peak. Diffractograms at low Bragg angles ( $2 \theta$ values from $0.5^{\circ}$ to $\left.4^{\circ}\right)$ were also carried out at $0.24^{\circ} \mathrm{min}^{-1}$ to study the ordered structure of OMC.

Nitrogen adsorption-desorption isotherms of OMC and gOMC were measured at $-196{ }^{\circ} \mathrm{C}$ using a Micromeritics ASAP 2020. The Brunauer, Emmett and Teller (BET) methodology was used to obtain the specific surface area $\left(\mathrm{S}_{\mathrm{BET}}\right)$, while total pore volume $\left(\mathrm{V}_{\mathrm{T}}\right)$ was determined using the single point method at $\mathrm{P} / \mathrm{P}_{0}=0.99$. The volume of 
mesopores $\left(V_{\text {meso }}\right)$ and the average pore diameter $\left(D_{p}\right)$ were obtained from the analysis of the desorption branch of the $\mathrm{N}_{2}$ isotherm using the Barrett, Joyner and Halenda (BJH) method. The mesopore contribution in terms of volume $(\%$ meso $)$ was estimated from $\mathrm{V}_{\text {meso }}$, considering the total pore volume.

X-ray photoelectron spectroscopy (XPS) analyses were carried out using an ESCAPlus OMICRON system with a hemispherical electron energy analyzer operating with a $\mathrm{MgK} \alpha \mathrm{X}$-ray source $(\mathrm{h} v=1253.6 \mathrm{eV})$ at $225 \mathrm{~W}$. Survey spectra were obtained from 0 to $1000 \mathrm{eV}$ at $0.5 \mathrm{eV}$ step, $0.2 \mathrm{~s}$ dwell and $50 \mathrm{eV}$ pass energy, while $\mathrm{C} 1 \mathrm{~s}$ and $\mathrm{O} 1 \mathrm{~s}$ highresolution spectra were recorded at $0.1 \mathrm{eV}$ step, $0.5 \mathrm{~s}$ dwell and $20 \mathrm{eV}$ pass energy. For calibration purposes, the $\mathrm{C} 1 \mathrm{~s}$ binding energy $(\mathrm{BE})$ of the graphitic peak was referenced at $284.5 \mathrm{eV}$. Shirley type background, peak fitting and quantification was performed by means of CasaXPS data processing software. Gaussian (40\%)-Lorentzian (60\%) profiles were used for each component, with the exception of the $\mathrm{C} \mathrm{sp}{ }^{2}$ contribution [52]. In this case an asymmetric peak shape was used, defined in CasaXPS as $\mathrm{A}(0.25,0.38,20) \mathrm{GL}(60)$ $[52,53]$.

\subsection{Electrooxidation tests}

Electrochemical measurements were carried out in a three-electrode electrochemical cell at room temperature using a high surface area carbon rod as counter electrode and a reversible hydrogen electrode (RHE) as reference. All potentials in the text are referred to this electrode. Gas diffusion electrodes (GDE) were used as working electrodes (area $=0.2 \mathrm{~cm}^{2}$ ). The working electrodes were prepared depositing $1 \mathrm{mg} \mathrm{cm}^{-2}$ of a carbon layer of the material under study on a carbon paper backing containing a gas diffusion layer (Sigracet ${ }^{\circledR}$ GDL 39BC). The carbon layer was composed of 67 wt.\% carbon and 33 wt. \% Nafion ${ }^{\circledR}$ ionomer (10 wt.\%, Aldrich) [27]. Electrochemical 
experiments were carried out using an Autolab PGSTAT302 (Metrohm) potentiostatgalvanostat.

All tests were carried out in deaerated $0.5 \mathrm{M} \mathrm{H}_{2} \mathrm{SO}_{4}$ aqueous solution. Accelerated stress tests were carried out for the evaluation of the carbon materials resistance to degradation. Among different stress test procedures published, including cyclic voltammetry [54] and chronoamperometry [41], we selected a potential holding test at $1.4 \mathrm{~V}$ vs RHE for $30 \mathrm{~min}$ under inert atmosphere. After electrooxidation, cyclic voltammograms $(\mathrm{CV})$ at $50 \mathrm{mV} \mathrm{s}^{-1}$ from 0.4 to $1.6 \mathrm{~V}$ vs. RHE were recorded to determine the capacitance of carbon materials. The capacitance was calculated from the integration of the area enclosed by the current vs. potential curve from 0.5 to $1.0 \mathrm{~V}$ vs RHE by considering the averaged value from positive and negative going scans. Finally, electrochemical impedance spectroscopy (EIS) measurements were carried out using a Frecuency Response Analyzer (FRA) at $1.4 \mathrm{~V}$ vs RHE in a frequency range from $100 \mathrm{kHz}$ to1 $\mathrm{Hz}$ by frequency sweeping in the single sine mode and recording 5 points per decade. The amplitude of the sinusoidal excitation signal was $0.01 \mathrm{~V}$ r.m.s.

$\mathrm{CV}$ and EIS of fresh electrodes (without electrochemical oxidation) were also performed in order to study the influence of electrochemical oxidation. Nitrogen was continuously fed to the electrode backing layer and to the electrolyte solution during all the electrochemical measurements.

\section{Results and discussion}

\subsection{Physicochemical characterization of ordered mesoporous carbons}

TEM images evidence the typical ordered honeycomb structure of OMC, consisting of carbon nanorods with uniform mesopores (Fig. 1). Comparing the bare (or untreated) materials (OMC-R2 and OMC-R5), an increase of the TEOS/P123 mass ratio from 2 to 5 led to a decrease of the ordering degree of mesoporous carbons, due to a 
decrease of the copolymer amount (P123). In acid media, P123 surfactant forms structures of interconnected liquid crystals, which drive the silica structuration and generate the ordered porosity after calcination. Therefore, the decrease of the P123 amount could produce the formation of not interconnected units leading to a lower ordering degree of carbon. On the other hand, graphitization procedure resulted in a decrease of the ordering degree of the resulting materials (gOMC-R2 and gOMC-R5) in comparison to untreated carbons (OMC-R2 and OMC-R5, respectively). In fact, gOMC-R5 suffered an important loss of the long-range organization after heat treatment. It is also noticeable in Fig. 1c and Fig. 1d that the cylindrical mesopores tend to bend forming circular ribbons of graphitic carbon.

Crystalline structural properties of OMC were studied by XRD (Fig. 2). Carbons prior to graphitization did not show diffraction between $2 \theta=10-80^{\circ}$, confirming that these materials present an amorphous nature. In contrast, graphitized carbons showed a broad peak at around $2 \theta=25^{\circ}$, which is associated to the graphite (002) diffraction line (Fig. 2a). This broad reflection is explained by the low size of graphite crystallites with $\mathrm{L}_{\mathrm{c}}$ values of 1.0 and $1.3 \mathrm{~nm}$ for gOMC-R2 and gOMC-R5, respectively. Thus, the heat treatment at $1500{ }^{\circ} \mathrm{C}$ led to a certain degree of crystallinity in OMC.

On the other hand, materials exhibit diffraction at low Bragg angles, as can be seen in Fig. 2b. OMC-R2 presented two clearly resolved peaks, indexed as (100) and (110) diffractions, associated to the formation of a highly ordered 2D hexagonal mesostructure (p6mm) [55]. In the case of OMC-R5, the (110) reflection is hardly discerned and the relative intensity of (100) is lower, indicating that an increase of the $\mathrm{R}$ ratio leads to a decrease of the structural ordering of the materials, in agreement with the results obtained from TEM images. 
Graphitization procedure resulted in a decrease of the ordering degree of OMC in comparison to that obtained with the original materials. In fact, the peaks indicative of highly ordered hexagonal mesostructure were not detected for gOMC-R5. In contrast, gOMC-R2 presented an evident diffraction, being the relative intensity of the graphite (100) peak at $2 \theta=1^{\circ}$ even higher than the carbons not treated thermally at $1500{ }^{\circ} \mathrm{C}$ and with a TEOS/P123 mass relation of 5 (OMC-R5). Therefore, the ratio $\mathrm{R}$ presents a stronger influence than the graphitization procedure onto the nanostructure of OMC.

Textural properties of OMC obtained by $\mathrm{N}_{2}$-physisorption are summarized in Table 1. As-synthesized mesoporous carbons showed a high specific surface area ( $\mathrm{S}_{\mathrm{BET}}$ $\left.=812-884 \mathrm{~m}^{2} \mathrm{~g}^{-1}\right)$ and pore volume $\left(\mathrm{V}_{\mathrm{T}}=0.55-0.59 \mathrm{~cm}^{3} \mathrm{~g}^{-1}\right)$ due to the particular synthesis methodology (hard-templating methodology). A decrease of the mass ratio $\mathrm{R}$ led to an increase of the adsorption capacity of OMC, which may be attributed to the longer-range organization of OMC-R2. These results confirm that it is possible to obtain OMC with the desired textural properties, by controlling the mass ratio $\mathrm{R}$ of the silica templates.

After graphitization treatments, the adsorption capacity of the samples decreased, which is ascribed to the partial loss of the ordering degree of carbon materials, as well as the removal of the microporosity by the surface annealing during the high temperature treatment. This effect is more evident for the sample OMC-R5, where the contribution of mesopores (in terms of pore volume) shifts from $56 \%$ for the original material to $82 \%$ upon graphitization. In this context, pore channels interconnected by micropores are essential for obtaining an ordered structure $[2,9,56]$. Thus, it seems that the carbon synthesized with $\mathrm{R}=5$ suffered a partial collapse of the structure during graphitization, leading to not interconnected pores and the removal of micropores. However, the treatment at high temperature did not present an important effect on the pore diameter. 
The atomic composition of OMC was studied by XPS. C1s spectra were deconvoluted in four contributions by Gaussian/Lorentzian fitting [51,52,57]: i) $\mathrm{sp}^{2}$ graphitic carbon $(\mathrm{C}=\mathrm{C})$ and $\mathrm{sp}^{3}$ hybridized carbon $(\mathrm{C}-\mathrm{C})$ were combined in an asymmetric peak at $284.5 \pm 0.0 \mathrm{eV}[51,52,57]$, ii) $\mathrm{C}-\mathrm{O}$ bonds in hydroxyls $(\mathrm{C}-\mathrm{OH})$ or epoxides $(\mathrm{C}-\mathrm{O}-$ C) at $286.7 \pm 0.3 \mathrm{eV}$, iii) $\mathrm{C}=\mathrm{O}$ bonds in carbonyls $(\mathrm{C}=\mathrm{O})$ or carboxyl $(\mathrm{O}=\mathrm{C}-\mathrm{OH})$ at 288.9 $\pm 0.2 \mathrm{eV}$ and iv) $\pi-\pi^{*}$ shake up satellite contribution at $290.9 \pm 0.0 \mathrm{eV}$ (Figure S1). The atomic compositions, calculated from the survey and the deconvoluted XPS C1s spectra analysis, are summarized in Table 2. Graphitization treatments led to a strong removal of surface oxygenates species, as can be seen in Table 2 .

\subsection{Electrooxidation studies}

Carbon electrooxidation was studied by chronoamperometric (CA) experiments at $1.4 \mathrm{~V}$ vs. RHE in $0.5 \mathrm{M} \mathrm{H}_{2} \mathrm{SO}_{4}$ aqueous solution and room temperature. At elevated potentials carbon electrooxidation proceeds through the equation 1 [36]. Fig. 3 shows the current-time curves (double logarithmic scale) obtained for OMC. Comparing the curves of bare OMC, a higher oxidation current is observed as the ratio TEOS/P123 decreases, which is explained by the differences in textural properties. OMC-R2 exhibited a higher surface area and total pore volume with a more developed mesoporosity, which facilitates the wettability of the carbon by the electrolyte, and hence the electrooxidation. For example, OMC-R2 showed a current density at $10 \mathrm{~s}$ around 2.5 times higher $\left(8.91 \mathrm{~A} \mathrm{~g}^{-1}\right)$ in comparison to its analogue synthesized with $\mathrm{R}=5\left(3.29 \mathrm{~A} \mathrm{~g} \mathrm{~g}^{-1}\right)$.

After graphitization, a noticeable decrease of the oxidation current was evident due to both the graphitization of the carbon material and the decrease of the surface area. This effect was more noticeable for OMC-R5 with a reduction in the current density at $10 \mathrm{~s}$ of $95 \%$. (from $3.29 \mathrm{~A} \mathrm{~g}^{-1}$ for the original carbon to $0.16 \mathrm{~A} \mathrm{~g}^{-1}$ for the heat treated material), while a decrease of $77 \%$ was exhibited by gOMC-R2 (from $8.91 \mathrm{~A} \mathrm{~g}^{-1}$ to 2.04 
$\mathrm{A}^{-1}$ ). Upon graphitization, the specific surface area decreases in the interval $35-50 \%$ (Table 1), while the surface oxygen content is reduced by one order of magnitude. The first modification contributes to a lower exposure of carbon atoms to the surface, while the second one may influence negatively the hydrophilicity of the material. These two aspects determine the promptness of carbon materials to be electrooxidized together with the ordering degree of carbon, i.e., the nature and strength of carbon bonding with neighboring species. In our case, we cannot discard any of these three factors influencing the larger resistance to electrooxidation of OMC upon graphitization.

The double-logarithmic representation of current vs. time in Fig. 3 results in quasilinear behavior, indicating that $\mathrm{OMC}$ behave according to Kinoshita-Giordano equation (equation 2) [58]:

$$
\mathrm{j}=\mathrm{k} \mathrm{t}^{-\mathrm{n}}
$$

where $j$ is the current density normalized per gram of carbon material $\left(\mathrm{A} \mathrm{g}^{-1}\right), t$ is the elapsed time and $k$ and $n$ are constants. Fitting parameters of the linear part of the curves are summarized in Table 3 . The slope $(n)$ generally gives an indication of the electrooxidation mechanism, ranging 0.65-0.79. The curves in Fig. 3 are parallel with slight differences at the very initial part, close to transient phenomena ascribed to the application of $1.4 \mathrm{~V}$ vs RHE, and at the very end of the curve, where graphitized OMC tend to a constant current at large times. In the central part of the curve, where most of the oxidation takes place in our experiments, OMC appear to be electrooxidized following a similar mechanism as indicated by similar slopes.

The main differences among carbon materials are thus found in the electrooxidation constant (k). Again, the OMC synthesized using the template with $\mathrm{R}=2$ oxidizes much faster than the one based on $\mathrm{R}=5$, which is ascribed to the more developed porosity allowing the aqueous electrolyte to penetrate the carbon layer at the electrode. A 
noticeable decrease of this oxidation constant is achieved by the graphitization procedure, especially in the case of gOMC-R5, where $\mathrm{k}$ is reduced more than one order of magnitude.

The oxidation-related charge, calculated from the area under the curves, was calculated for the first $30 \mathrm{~min}$ of experiments and the data are also included in Table 3. The results in terms of charge are in line with the previous discussion of kinetic parameters, with more than $50 \%$ reduction of oxidation extent in the case of OMC-R2 upon graphitization and more than $90 \%$ in the case of OMC-R5. This highlights that the graphitization process influences differently OMC materials electrooxidation, the latter relying on the original properties of the bare materials and, in our case, on the template characteristics.

Cyclic voltammograms were recorded at $50 \mathrm{mV} \mathrm{s}^{-1}$ to study the influence of electrooxidation tests on the electrochemical behavior and capacitance of carbon materials. Fig. 4 shows the current density vs potential curves for fresh electrodes (black solid line) and upon potential holding at $1.4 \mathrm{~V}$ vs. RHE for $30 \mathrm{~min}$ (red dashed line). Table 3 summarizes the capacitance of the electrodes before $\left(\mathrm{C}_{\mathrm{t}=0}\right)$ and after $\left(\mathrm{C}_{\mathrm{t}=30}\right)$ oxidation tests, as well as the relative variation (\%). The capacitance was calculated between 0.5 and $1.0 \mathrm{~V}$ vs. RHE, in a potential window where no faradaic reactions occur. Interestingly, a different behavior was evidenced for $\mathrm{OMC}$ and gOMC: bare carbon materials (OMC-R2 and OMC-R5) showed a decrease of the capacitance after electrooxidation studies, whereas in the case of graphitized carbons (gOMC-R2 and gOMC-R5) a significant increase of the double layer current was observed. The decrease of the capacitance for as-synthesized carbons may be related to the destruction of the porous structure of the materials by the irreversible degradation of carbon by electrooxidation (equation 1) during chronoamperometry tests at $1.4 \mathrm{~V}$ vs. RHE. A similar behavior has been evidenced in previous works after progressive cycling of 
different carbon materials $[43,44,59,60]$. On the other hand, the increase of the capacitance for graphitized carbons may be ascribed to the surface oxidation dealing to the creation of oxygenated species and or defects during potential holding $[27,43,44,59,60]$. Oxygen species favor the wettability of carbon by the electrolyte, and consequently a higher capacitance is obtained. These results show that graphitization treatments led to lower tendency to undergo irreversible electrooxidation of carbon to $\mathrm{CO}_{2}$, in agreement with the results explained above.

Electrochemical impedance spectroscopy (EIS) is a useful technique to individuate the different processes occurring at the electrode/electrolyte interface. We carried out EIS measurements at $1.4 \mathrm{~V}$ vs. RHE. Fig. 5a and 5b shows the Bodeimpedance and Bode-phase plots, respectively, for the various electrodes before (black) and after (red) chronoamperometric experiments. Fresh electrodes were utilized in every experiment, accounting for EIS and chronoamperometry, to avoid any influence of EIS on the chronoamperometric behavior.

At high frequencies $(>10 \mathrm{kHz})$, where the phase is closer to zero (Fig. 5b), the impedance represented in Fig. 5a can be ascribed to equivalent series resistance $\left(R_{s}\right)$ of the cell. This resistance comprises the internal resistance of the electrode and electrolyte, in addition to the contact resistance at the carbon material/current collector interface. $R_{S}$ is similar for all the OMCs before chronoamperometry (black curves, $1.8 \Omega \mathrm{cm}^{2}$ ) except for OMC-R2 electrode, which exhibits a significantly higher series resistance of $5.7 \Omega$ $\mathrm{cm}^{2}$. The latter can be ascribed to the poorer electrical conductivity of the carbon film at the electrode for this material in particular, as also evident in CV experiments (Fig. 4). Upon electrooxidation, the series resistance of OMC-R5 and gOMC-R5 increases slightly, indicating a higher resistivity to electron conduction. This might be caused by the formation of oxygen species. 
At lower frequencies, important differences in the impedance values were found, first depending on the characteristics of the bare OMC and secondly upon the potential holding tests. Only OMC-R5 exhibits a characteristic frequency in the order of 100-1000 Hz. This can be ascribed to the electrooxidation of carbon at $1.4 \mathrm{~V}$ vs. RHE. In the other electrodes, capacitive behavior governs the impedance in a larger extent than the electrooxidation process.

XPS analyses were carried out on the electrodes before and after the chronoamperometric tests in order to scrutinize eventual changes in chemical composition at the surface. Table 4 summarizes the relative content of carbon, oxygen, sulfur and fluorine according to the survey spectra. The binder used to prepare the electrodes, Nafion ${ }^{\circledR}$, is based on a perfluorosulfonic acid polymer, with chemical formula $\left(\mathrm{C}_{7} \mathrm{HF}_{13} \mathrm{O}_{5} \mathrm{~S}\right)_{\mathrm{m}} \cdot\left(\mathrm{C}_{2} \mathrm{~F}_{4}\right)_{\mathrm{n}}$. This is the reason of fluorine representing almost half of the atomic percentage in the electrodes. Both the carbon materials and the binder contribute to the signals of $\mathrm{C} 1 \mathrm{~s}$ and $\mathrm{O} 1 \mathrm{~s}$, but only the binder exhibits F1s and S2p speciation. Similar contents of Nafion ${ }^{\circledR}$ in the fresh electrodes can be considered, with F representing 45-48 at $\%$ of total composition and very similar S/F ratios around 0.03 coming from the binder. We can therefore confirm that similar contents of Nafion ${ }^{\circledR}$ were present in the electrodes. As a matter of fact, the relative amount of fluorine increases upon electrooxidation while carbon content decreases for all the electrodes. This is a clear indication that carbon is partially lost as $\mathrm{CO}_{2}$ during the potential holding experiment. On the other hand, the $\mathrm{S} / \mathrm{F}$ ratio decreases to some extent, especially in the electrodes prepared with the graphitized OMCs, which may be attributed to a slight decrease of the content of sulfonic groups $\left(\mathrm{SO}_{3}{ }^{-}\right)$in the binder. This partial loss of sulfonic groups should contribute to the decrease of oxygen signal. Instead, the relative amount of $\mathrm{O}$ increases for the whole set of electrodes upon potential holding (CA). Keeping in mind all these aspects, the relative 
amount of oxygen and carbon can be considered as a good estimation to evaluate changes in oxygen species at the surface of the electrodes.

The variation in the relative amount of oxygen with respect to carbon is better highlighted in Fig. 6. Two different normalizations have been considered: taking into account the total amount of carbon $\mathrm{C} 1 \mathrm{~s}\left(\mathrm{C}_{\text {total }}\right)$, which includes carbon bond to fluorine in the binder and carbon-oxygen species together with $\mathrm{sp}^{2}$ carbon; and considering only the last one $\left(\mathrm{C} \mathrm{sp}^{2}\right)$, in order to better individuate carbon species related to OMC. In general terms, the amount of oxygen is larger in non-graphitized OMCs if compared to gOMCs. As expected, the thermal treatment leads to the loss of oxygen in the carbonaceous substrate. The relative amount of oxygen in the bare electrodes (before chronoamperometry) is in line with the XPS analyses of carbon materials (Table 2), considering the differences in the electrodes as a consequence of the presence of the binder.

More interesting is the analysis of oxygen-to-carbon ratios upon electrooxidation. The results of Fig. 6 evidence an increase of oxygen concentration after chronoamperometric experiments regardless the composition of the electrode, both in terms of $\mathrm{O} / \mathrm{C}_{\text {total }}$ and $\mathrm{O} / \mathrm{Csp}^{2}$. The surface of carbon is therefore enriched in oxygen content upon potential holding despite the loss of a small amount of sulfonic groups. According to the works of Gallagher and coworkers $[47,48]$, the electrooxidation of carbon proceeds through several reactions including the formation of phenols, hydroxides, carbonyl/quinones and carboxylic acid. The latter species can eventually oxidize to carbon dioxide, being this reaction the rate determining step. $\mathrm{C} 1 \mathrm{~s}$ spectra were deconvoluted in five contributions by Gaussian/Lorentzian fitting (Figure S2). In addition to $\mathrm{sp}^{2}$ graphitic carbon $(\mathrm{C}=\mathrm{C})$ contribution (at $284.5 \mathrm{eV} \pm 0.0$ ), $\mathrm{C}-\mathrm{O}$ bonds (at $286.8 \pm$ 0.3 ) and $\mathrm{C}=\mathrm{O}$ bonds (at $289.2 \pm 0.1$ ), two peaks were considered at $291.8 \pm 0.1 \mathrm{eV}$ and 
$293 \pm 0.4 \mathrm{eV}$ related to the CF2 and CF3 groups in the Nafion structure, respectively. The analysis of $\mathrm{C} 1 \mathrm{~s}$ peak in XPS evidenced a certain increase of C-O functionalities in OMCR2 and gOMC-R5 after the chronoamperometric experiment. Only gOMC-R5 exhibited a significant variation of $\mathrm{C}=\mathrm{O}$ relative content, implying that this graphitized $\mathrm{OMC}$ is more prone to form oxygen species like carboxylic acids or quinone.

\section{Conclusions}

Two different ordered mesoporous carbons have been synthesized and thermally treated at $1500{ }^{\circ} \mathrm{C}$ to induce graphitization. These materials have been investigated for the electrooxidation of carbon at room temperature and $1.4 \mathrm{~V}$ vs. RHE in $0.5 \mathrm{M} \mathrm{H}_{2} \mathrm{SO}_{4}$. The main physicochemical properties, including surface area, pore volume and chemical composition have been evaluated in order to establish a correlation with the electrochemical behaviour. Graphitization resulted in an important decrease of the electrooxidation associated charge (50-90\%) depending on the carbon nature which may be ascribed to the reduction of the specific surface area (around 35-50\%) and the surface oxygen amount during the heat temperature treatment, as well as the increase of the carbon ordering degree. Cyclic voltammetry and electrochemical impedance measurements showed that the graphitized carbon materials still present a large surface area. By comparison of XPS analysis of the fresh and electrooxidized electrodes, an increase of the relative amount of oxygen was evidenced upon potential holding for both as-synthesized and graphitized materials.

\section{Acknowledgments}

The authors gratefully acknowledge financial support given by Spanish Ministry of Science, Innovation and Universities MICINN (ENE2017-83976-C2-1-R) and to the Aragón Government to the Fuel Conversion Group (T06_17R). DS acknowledges also MICINN for his Ramón y Cajal contract (RyC-2016-20944). Furthermore, the authors 
wish to thank Dra. Ana Beatriz García (INCAR-CSIC) for the graphitization treatment of OMC.

\section{References}

[1] A. Walcarius, Electrocatalysis, sensors and biosensors in analytical chemistry based on ordered mesoporous and macroporous carbon-modified electrodes, TrAC Trends Anal. Chem. 38 (2012) 79-97. doi:http://dx.doi.org/10.1016/j.trac.2012.05.003.

[2] A. Walcarius, Mesoporous materials and electrochemistry, Chem. Soc. Rev. 42 (2013) 4098. doi:10.1039/c2cs35322a.

[3] M. Hartmann, Ordered Mesoporous Materials for Bioadsorption and Biocatalysis, Chem. Mater. 17 (2005) 4577-4593. doi:10.1021/cm0485658.

[4] H. Nishihara, T. Kyotani, Templated Nanocarbons for Energy Storage, Adv. Mater. 24 (2012) 4473-4498. doi:10.1002/adma.201201715.

[5] C. Vix-Guterl, E. Frackowiak, K. Jurewicz, M. Friebe, J. Parmentier, F. Béguin, Electrochemical energy storage in ordered porous carbon materials, Carbon N. Y. 43 (2005) 1293-1302. doi:http://dx.doi.org/10.1016/j.carbon.2004.12.028.

[6] C. Vix-Guterl, S. Saadallah, K. Jurewicz, E. Frackowiak, M. Reda, J. Parmentier, J. Patarin, F. Beguin, Supercapacitor electrodes from new ordered porous carbon materials obtained by a templating procedure, Mater. Sci. Eng. B. 108 (2004) 148-155. doi:http://dx.doi.org/10.1016/j.mseb.2003.10.096.

[7] K. Jurewicz, C. Vix-Guterl, E. Frackowiak, S. Saadallah, M. Reda, J. Parmentier, J. Patarin, F. Béguin, Capacitance properties of ordered porous carbon materials prepared by a templating procedure, J. Phys. Chem. Solids. 65 (2004) 287-293. doi:http://dx.doi.org/10.1016/j.jpcs.2003.10.024.

[8] H. Chang, S.H. Joo, C. Pak, Synthesis and characterization of mesoporous carbon 
for fuel cell applications, J. Mater. Chem. 17 (2007) 3078-3088.

doi:10.1039/B700389G.

[9] E. Antolini, Carbon supports for low-temperature fuel cell catalysts, Appl. Catal. B Environ. 88 (2009) 1-24. doi:http://dx.doi.org/10.1016/j.apcatb.2008.09.030.

[10] C.-D. Dong, C.-W. Chen, C.-F. Chen, C.-M. Hung, Platinum particles supported on mesoporous carbons: fabrication and electrocatalytic performance in methanol-tolerant oxygen-reduction reactions, Sci. Rep. 4 (2015) 5790. doi:10.1038/srep05790.

[11] E.P. Ambrosio, C. Francia, M. Manzoli, N. Penazzi, P. Spinelli, Platinum catalyst supported on mesoporous carbon for PEMFC, Int. J. Hydrogen Energy. 33 (2008) 3142-3145. doi:http://dx.doi.org/10.1016/j.ijhydene.2008.03.045.

[12] S. Song, K. Wang, Y. Liu, C. He, Y. Liang, R. Fu, D. Wu, Y. Wang, Highly ordered mesoporous carbons as the support for Pt catalysts towards alcohol electrooxidation: The combined effect of pore size and electrical conductivity, Int. J. Hydrogen Energy. 38 (2013) 1405-1412. doi:10.1016/j.ijhydene.2012.11.029.

[13] L. Calvillo, M.J. Lázaro, E. García-Bordejé, R. Moliner, P.L. Cabot, I. Esparbé, E. Pastor, J.J. Quintana, Platinum supported on functionalized ordered mesoporous carbon as electrocatalyst for direct methanol fuel cells, J. Power Sources. 169 (2007) 59-64. doi:10.1016/j.jpowsour.2007.01.042.

[14] J.R.C. Salgado, F. Alcaide, G. Álvarez, L. Calvillo, M.J. Lázaro, E. Pastor, Pt-Ru electrocatalysts supported on ordered mesoporous carbon for direct methanol fuel cell, J. Power Sources. 195 (2010) 4022-4029. doi:http://dx.doi.org/10.1016/j.jpowsour.2010.01.001.

[15] S.H. Joo, C. Pak, D.J. You, S.-A. Lee, H.I. Lee, J.M. Kim, H. Chang, D. Seung, 
Ordered mesoporous carbons (OMC) as supports of electrocatalysts for direct methanol fuel cells (DMFC): Effect of carbon precursors of OMC on DMFC performances, Electrochim. Acta. 52 (2006) 1618-1626.

doi:10.1016/J.ELECTACTA.2006.03.092.

[16] G. Chai, S.B. Yoon, S. Kang, J.H. Choi, Y.E. Sung, Y.S. Ahn, H.S. Kim, J.S. Yu, Ordered uniform porous carbons as a catalyst support in a direct methanol fuel cell, Electrochim. Acta. 50 (2004) 823-826.

doi:http://dx.doi.org/10.1016/j.electacta.2003.11.041.

[17] J. Zeng, C. Francia, M.A. Dumitrescu, A.H.A. Monteverde Videla, V.S. Ijeri, S. Specchia, P. Spinelli, Electrochemical performance of Pt-based catalysts supported on different ordered mesoporous carbons (Pt/OMCs) for oxygen reduction reaction, Ind. Eng. Chem. Res. 51 (2012) 7500-7509. doi:10.1021/ie2016619.

[18] J. Zeng, C. Francia, C. Gerbaldi, V. Baglio, S. Specchia, A.S. Aricò, P. Spinelli, Hybrid ordered mesoporous carbons doped with tungsten trioxide as supports for Pt electrocatalysts for methanol oxidation reaction, Electrochim. Acta. 94 (2013) 80-91. doi:10.1016/j.electacta.2013.01.139.

[19] J.Y. Cheon, T. Kim, Y. Choi, H.Y. Jeong, M.G. Kim, Y.J. Sa, J. Kim, Z. Lee, T.H. Yang, K. Kwon, O. Terasaki, G.-G. Park, R.R. Adzic, S.H. Joo, Ordered mesoporous porphyrinic carbons with very high electrocatalytic activity for the oxygen reduction reaction., Sci. Rep. 3 (2013) 2715. doi:10.1038/srep02715.

[20] A.H.A. Monteverde Videla, L. Osmieri, M. Armandi, S. Specchia, Varying the morphology of Fe-N-C electrocatalysts by templating Iron Phthalocyanine precursor with different porous SiO\&lt;inf\&gt;2\&lt;/inf\&gt; to promote the Oxygen Reduction Reaction, Electrochim. Acta. 177 (2015) 43-50. 
doi:10.1016/j.electacta.2015.01.165.

[21] L. Osmieri, A.H.A. Monteverde Videla, S. Specchia, Optimization of a Fe-N-C electrocatalyst supported on mesoporous carbon functionalized with polypyrrole for oxygen reduction reaction under both alkaline and acidic conditions, Int. J. Hydrogen Energy. 41 (2016) 19610-19628. doi:10.1016/j.ijhydene.2016.05.270.

[22] L. Osmieri, R. Escudero-Cid, M. Armandi, A.H.A. Monteverde Videla, J.L. García Fierro, P. Ocón, S. Specchia, Fe-N/C catalysts for oxygen reduction reaction supported on different carbonaceous materials. Performance in acidic and alkaline direct alcohol fuel cells, Appl. Catal. B Environ. 205 (2017) 637653. doi:10.1016/j.apcatb.2017.01.003.

[23] M.M. Hossen, K. Artyushkova, P. Atanassov, A. Serov, Synthesis and characterization of high performing Fe-N-C catalyst for oxygen reduction reaction (ORR) in Alkaline Exchange Membrane Fuel Cells, J. Power Sources. 375 (2018) 214-221. doi:10.1016/j.jpowsour.2017.08.036.

[24] A. Serov, K. Artyushkova, P. Atanassov, Fe-N-C Oxygen Reduction Fuel Cell Catalyst Derived from Carbendazim: Synthesis, Structure, and Reactivity, Adv. Energy Mater. 4 (2014) 1301735. doi:10.1002/aenm.201301735.

[25] K. Artyushkova, A. Serov, S. Rojas-Carbonell, P. Atanassov, Chemistry of Multitudinous Active Sites for Oxygen Reduction Reaction in Transition MetalNitrogen-Carbon Electrocatalysts, J. Phys. Chem. C. 119 (2015) 25917-25928. doi:10.1021/acs.jpcc.5b07653.

[26] D. Sebastián, A. Serov, I. Matanovic, K. Artyushkova, P. Atanassov, A.S. Aricò, V. Baglio, Insights on the extraordinary tolerance to alcohols of Fe-N-C cathode catalysts in highly performing direct alcohol fuel cells, Nano Energy. 34 (2017) 195-204. doi:10.1016/j.nanoen.2017.02.039. 
[27] V. Celorrio, D. Sebastián, L. Calvillo, A.B. García, D.J. Fermin, M.J. Lázaro, Influence of thermal treatments on the stability of Pd nanoparticles supported on graphitised ordered mesoporous carbons, Int. J. Hydrogen Energy. 41 (2016) 19570-19578. doi:10.1016/J.IJHYDENE.2016.05.271.

[28] H. Darmstadt, C. Roy, S. Kaliaguine, S.J. Choi, R. Ryoo, Surface chemistry of ordered mesoporous carbons, Carbon N. Y. 40 (2002) 2673-2683. doi:http://dx.doi.org/10.1016/S0008-6223(02)00187-2.

[29] T.-W. Kim, I.-S. Park, R. Ryoo, A Synthetic Route to Ordered Mesoporous Carbon Materials with Graphitic Pore Walls, Angew. Chemie Int. Ed. 42 (2003) 4375-4379. doi:10.1002/anie.200352224.

[30] H. Darmstadt, C. Roy, S. Kaliaguine, S.H. Joo, R. Ryoo, Pore structure and graphitic surface nature of ordered mesoporous carbons probed by low-pressure nitrogen adsorption, Microporous Mesoporous Mater. 60 (2003) 139-149. doi:http://dx.doi.org/10.1016/S1387-1811(03)00335-4.

[31] K.P. Gierszal, M. Jaroniec, T.-W. Kim, J. Kim, R. Ryoo, High temperature treatment of ordered mesoporous carbons prepared by using various carbon precursors and ordered mesoporous silica templates, New J. Chem. 32 (2008) 981. doi:10.1039/b716735k.

[32] D. Nettelroth, H.-C. Schwarz, N. Burblies, N. Guschanski, P. Behrens, Catalytic graphitization of ordered mesoporous carbon CMK-3 with iron oxide catalysts: Evaluation of different synthesis pathways, Phys. Status Solidi. 213 (2016) 13951402. doi:10.1002/pssa.201532796.

[33] M. Sevilla, A.B. Fuertes, Catalytic graphitization of templated mesoporous carbons, Carbon N. Y. 44 (2006) 468-474.

doi:10.1016/J.CARBON.2005.08.019. 
[34] K.N. Sultana, A.L. Fadhel, V.G. Deshmane, S. Ilias, Novel method for synthesis of electrocatalyst via catalytic graphitization of ordered mesoporous carbon for PEMFC application, Sep. Sci. Technol. 53 (2018) 1948-1956. doi:10.1080/01496395.2017.1290657.

[35] J. Calderón Gómez, V. Celorrio, L. Calvillo, D. Sebastián, R. Moliner, M. Lázaro Elorri, J.C. Calderón Gómez, V. Celorrio, L. Calvillo, D. Sebastián, R. Moliner, M.J. Lázaro Elorri, Electrochemical Behavior of Pt-Ru Catalysts Supported on Graphitized Ordered Mesoporous Carbons toward CO and Methanol Oxidation, Surfaces. 2 (2019) 1-15. doi:10.3390/surfaces2010001.

[36] S. Maass, F. Finsterwalder, G. Frank, R. Hartmann, C. Merten, Carbon support oxidation in PEM fuel cell cathodes, J. Power Sources. 176 (2008) 444-451. doi:10.1016/J.JPOWSOUR.2007.08.053.

[37] C.-C. Hung, P.-Y. Lim, J.-R. Chen, H.C. Shih, Corrosion of carbon support for PEM fuel cells by electrochemical quartz crystal microbalance, J. Power Sources. 196 (2011) 140-146. doi:10.1016/J.JPOWSOUR.2010.07.015.

[38] S.J. Ashton, M. Arenz, A DEMS study on the electrochemical oxidation of a high surface area carbon black, Electrochem. Commun. 13 (2011) 1473-1475. doi:10.1016/J.ELECOM.2011.09.024.

[39] F. Forouzandeh, X. Li, D.W. Banham, F. Feng, S. Ye, V. Birss, Understanding the Corrosion Resistance of Meso- and Micro-Porous Carbons for Application in PEM Fuel Cells, J. Electrochem. Soc. 165 (2018) F3230-F3240. doi:10.1149/2.0261806jes.

[40] F. Forouzandeh, X. Li, D.W. Banham, F. Feng, S. Ye, V. Birss, Evaluation of the Corrosion Resistance of Carbons for Use as PEM Fuel Cell Cathode Supports, J. Electrochem. Soc. 162 (2015) F1333-F1341. doi:10.1149/2.0381512jes. 
[41] C. Alegre, D. Sebastián, M.J. Lázaro, Carbon xerogels electrochemical oxidation and correlation with their physico-chemical properties, Carbon N. Y. 144 (2019) 382-394. doi:10.1016/J.CARBON.2018.12.065.

[42] B. Avasarala, R. Moore, P. Haldar, Surface oxidation of carbon supports due to potential cycling under PEM fuel cell conditions, Electrochim. Acta. 55 (2010) 4765-4771. doi:10.1016/J.ELECTACTA.2010.03.056.

[43] V.A. Golovin, N.V. Maltseva, E.N. Gribov, A.G. Okunev, New nitrogencontaining carbon supports with improved corrosion resistance for proton exchange membrane fuel cells, Int. J. Hydrogen Energy. 42 (2017) 11159-11165. doi:10.1016/J.IJHYDENE.2017.02.117.

[44] E.N. Gribov, N.V. Maltseva, V.A. Golovin, A.G. Okunev, A simple method for estimating the electrochemical stability of the carbon materials, Int. J. Hydrogen Energy. 41 (2016) 18207-18213. doi:10.1016/J.IJHYDENE.2016.08.118.

[45] N. Macauley, D.D. Papadias, J. Fairweather, D. Spernjak, D. Langlois, R. Ahluwalia, K.L. More, R. Mukundan, R.L. Borup, Carbon Corrosion in PEM Fuel Cells and the Development of Accelerated Stress Tests, J. Electrochem. Soc. 165 (2018) F3148-F3160. doi:10.1149/2.0061806jes.

[46] K.G. Gallagher, G. Yushin, T.F. Fuller, The Role of Nanostructure in the Electrochemical Oxidation of Model-Carbon Materials in Acidic Environments, J. Electrochem. Soc. 157 (2010) B820. doi:10.1149/1.3374662.

[47] K.G. Gallagher, T.F. Fuller, Kinetic model of the electrochemical oxidation of graphitic carbon in acidic environments, Phys. Chem. Chem. Phys. 11 (2009) 11557. doi:10.1039/b915478g.

[48] K.G. Gallagher, D.T. Wong, T. Fuller, The Effect of Transient Potential Exposure on the Electrochemical Oxidation of Carbon Black in Low- 
Temperature Fuel Cells, in: ECS Trans., ECS, 2007: pp. 993-1002. doi:10.1149/1.2781012.

[49] R. Berenguer, R. Ruiz-Rosas, A. Gallardo, D. Cazorla-Amorós, E. Morallón, H. Nishihara, T. Kyotani, J. Rodríguez-Mirasol, T. Cordero, Enhanced electrooxidation resistance of carbon electrodes induced by phosphorus surface groups, Carbon N. Y. 95 (2015) 681-689. doi:10.1016/J.CARBON.2015.08.101.

[50] L. Calvillo, V. Celorrio, R. Moliner, P.L. Cabot, I. Esparbé, M.J. Lázaro, Control of textural properties of ordered mesoporous materials, Microporous Mesoporous Mater. 116 (2008) 292-298. doi:10.1016/j.micromeso.2008.04.015.

[51] S. Pérez-Rodríguez, D. Torres, M.J. Lázaro, Effect of oxygen and structural properties on the electrical conductivity of powders of nanostructured carbon materials, Powder Technol. 340 (2018) 380-388. doi:10.1016/J.POWTEC.2018.09.038.

[52] D. Torres, J.L. Pinilla, I. Suelves, Unzipping of multi-wall carbon nanotubes with different diameter distributions: Effect on few-layer graphene oxide obtention, Appl. Surf. Sci. 424 (2017) 101-110. doi:10.1016/J.APSUSC.2017.01.273.

[53] H. Estrade-Szwarckopf, XPS photoemission in carbonaceous materials: A “defect” peak beside the graphitic asymmetric peak, Carbon N. Y. 42 (2004) 1713-1721. doi:10.1016/J.CARBON.2004.03.005.

[54] A. Ohma, K. Shinohara, A. Iiyama, T. Yoshida, A. Daimaru, Membrane and Catalyst Performance Targets for Automotive Fuel Cells by FCCJ Membrane, Catalyst, MEA WG, in: ECS Trans., The Electrochemical Society, 2011: pp. 775-784. doi:10.1149/1.3635611.

[55] D. Zhao, J. Feng, Q. Huo, N. Melosh, G.H. Fredrickson, B.F. Chmelka, G.D. Stucky, Triblock Copolymer Syntheses of Mesoporous Silica with Periodic 50 to 
300 Angstrom Pores, Science (80-. ). 279 (1998) 548-552.

doi:10.1126/science.279.5350.548.

[56] Y. Xia, Z. Yang, R. Mokaya, Templated nanoscale porous carbons, Nanoscale. 2 (2010) 639. doi:10.1039/b9nr00207c.

[57] D. Torres, P. Arcelus-Arrillaga, M. Millan, J. Pinilla, I. Suelves, D. Torres, P. Arcelus-Arrillaga, M. Millan, J.L. Pinilla, I. Suelves, Enhanced Reduction of Few-Layer Graphene Oxide via Supercritical Water Gasification of Glycerol, Nanomaterials. 7 (2017) 447. doi:10.3390/nano7120447.

[58] K. Kinoshita, J. Bett, Electrochemical oxidation of carbon black in concentrated phosphoric acid at $135^{\circ} \mathrm{C}$, Carbon N. Y. 11 (1973) 237-247. doi:10.1016/00086223(73)90026-2.

[59] S. Pérez-Rodríguez, D. Sebastián, M.J. Lázaro, E. Pastor, Stability and catalytic properties of nanostructured carbons in electrochemical environments, J. Catal. 355 (2017). doi:10.1016/j.jcat.2017.09.019.

[60] S. Pérez-Rodríguez, E. Pastor, M.J. Lázaro, Electrochemical behavior of the carbon black Vulcan XC-72R: Influence of the surface chemistry, Int. J. Hydrogen Energy. (2018). doi:10.1016/j.ijhydene.2018.03.040. 
Table 1. Textural parameters of ordered mesoporous carbons.

\begin{tabular}{|c|c|c|c|c|c|}
\hline Carbon & $\begin{array}{c}\mathbf{S}_{\text {BET }} \\
\left(\mathbf{m}^{\mathbf{2}} \mathbf{g}^{-1}\right)\end{array}$ & $\begin{array}{c}\mathbf{V}_{\mathbf{T}} \\
\left(\mathbf{c m}^{\mathbf{3}} \mathbf{g}^{-\mathbf{1}}\right)\end{array}$ & $\begin{array}{c}\mathbf{V}_{\mathbf{m e s o}} \\
\left(\mathbf{c m}^{\mathbf{3}} \mathbf{g}^{-\mathbf{1}}\right)\end{array}$ & $\mathbf{\%}$ meso & $\begin{array}{c}\mathbf{D}_{\mathbf{p}} \\
(\mathbf{n m})\end{array}$ \\
\hline OMC-R2 & 884 & 0.59 & 0.39 & 66 & 3.0 \\
\hline OMC-R5 & 812 & 0.55 & 0.31 & 56 & 3.8 \\
\hline gOMC-R2 & 576 & 0.41 & 0.27 & 68 & 3.0 \\
\hline gOMC-R5 & 417 & 0.33 & 0.27 & 82 & 3.6 \\
\hline
\end{tabular}

Table 2. $\mathrm{C}$ and $\mathrm{O}$ amount obtained from XPS and deconvolution of C1s high-resolution spectra of ordered mesoporous carbons.

\begin{tabular}{|c|c|c|c|c|c|c|c|}
\hline Carbon & $\begin{array}{c}\mathbf{C} \\
(\mathbf{a t} \%)\end{array}$ & $\begin{array}{c}\mathbf{O} \\
(\mathbf{a t} \%)\end{array}$ & $\mathbf{C / O}$ & $\begin{array}{c}\mathbf{C s p}^{2} \\
(\boldsymbol{\%})\end{array}$ & $\begin{array}{c}\mathbf{C - O} \\
(\boldsymbol{\%})\end{array}$ & $\begin{array}{c}\mathbf{C = O} \\
(\boldsymbol{\%})\end{array}$ & $\begin{array}{c}\boldsymbol{\pi}-\boldsymbol{\pi}^{*} \\
(\boldsymbol{\%})\end{array}$ \\
\hline OMC-R2 & 93.8 & 6.1 & 15.4 & 86.6 & 2.83 & 6.6 & 4.0 \\
\hline OMC-R5 & 91.4 & 8.6 & 10.6 & 77.7 & 11.2 & 6.6 & 4.5 \\
\hline gOMC-R2 & 99.4 & 0.6 & 167 & 77.2 & 12.4 & 4.4 & 6.1 \\
\hline gOMC-R5 & 99.5 & 0.5 & 199 & 77.0 & 12.5 & 3.9 & 6.7 \\
\hline
\end{tabular}

Table 3. Electrooxidation parameters of ordered mesoporous carbons.

\begin{tabular}{|c|c|c|c|c|c|c|}
\hline Electrode & $\begin{array}{c}k \\
\left(A s^{n} g^{-1}\right)\end{array}$ & $\mathbf{n}$ & $\begin{array}{c}\text { Carbon oxidation } \\
\text { charge in } 30 \text { min } \\
\left(\mathrm{C} \mathrm{g} \mathrm{g}^{-1}\right)\end{array}$ & $\begin{array}{c}\mathbf{C}_{\mathrm{t}=\mathbf{0}} \\
\left(\mathbf{F ~ g ~}^{-1}\right)\end{array}$ & $\begin{array}{l}C_{t=30} \\
\left(F^{-1}\right)\end{array}$ & $\frac{C_{t=30}-C_{t=0}}{C_{t=0}}(\%)$ \\
\hline OMC-R2 & 61.4 & 0.79 & 1098 & 26 & 21 & -20 \\
\hline OMC-R5 & 24.4 & 0.72 & 574 & 15 & 5 & -68 \\
\hline gOMC-R2 & 9.2 & 0.65 & 431 & 7 & 67 & 806 \\
\hline gOMC-R5 & 0.77 & 0.67 & 48 & 5 & 10 & 101 \\
\hline
\end{tabular}


Table 4. Chemical speciation from XPS analysis to the electrodes before and after chronoamperometric (CA) experiments at $1.4 \mathrm{~V}$ vs. RHE.

\begin{tabular}{|c|c|c|c|c|c|c|c|c|}
\cline { 5 - 8 } \\
\hline Electrode & C (at \%) & O (at\%) & S (at\%) & F (at\%) & Csp $\mathbf{~}^{(\%)}$ & C-O (\%) & C=O (\%) & S/F \\
\hline OMC-R2 & 43.6 & 5.9 & 1.5 & 48.9 & 12.6 & 1.65 & 3.26 & 0.031 \\
\hline OMC-R2 CA & 36.1 & 7.2 & 1.6 & 55.1 & 14.6 & 2.52 & 1.69 & 0.029 \\
\hline gOMC-R2 & 48.2 & 4.7 & 1.3 & 45.8 & 22.0 & 5.53 & 5.71 & 0.028 \\
\hline gOMC-R2 CA & 41.2 & 5.1 & 1.1 & 52.6 & 20.4 & 4.76 & 5.68 & 0.021 \\
\hline OMC-R5 & 45.5 & 6.3 & 1.5 & 46.6 & 19.4 & 4.20 & 3.27 & 0.033 \\
\hline OMC-R5 CA & 42.6 & 6.9 & 1.5 & 48.9 & 18.6 & 4.20 & 3.67 & 0.032 \\
\hline gOMC-R5 & 48.0 & 4.8 & 1.4 & 45.8 & 17.9 & 4.97 & 5.99 & 0.031 \\
\hline gOMC-R5 CA & 39.5 & 4.5 & 1.2 & 54.8 & 16.5 & 5.88 & 7.45 & 0.022 \\
\hline
\end{tabular}




\section{FIGURE CAPTIONS}

Figure 1. TEM images of ordered mesoporous carbons: OMC-R2 (a), OMC-R5 (b), gOMC-R2 (c), gOMC-R5 (d).

Figure 2. XRD patterns of ordered mesoporous carbons (a) and XRD patterns at low Bragg angles (b).

Figure 3. Current-time curves for electrooxidation tests at $1.4 \mathrm{~V}$ in $0.5 \mathrm{M} \mathrm{H}_{2} \mathrm{SO}_{4}$ of ordered mesoporous carbons.

Figure 4. $\mathrm{CV}$ from 0.4 to $1.6 \mathrm{~V}^{-1}$ vs $\mathrm{RHE}$ at $50 \mathrm{mV} \mathrm{s}$ in $0.5 \mathrm{M} \mathrm{H}_{2} \mathrm{SO}_{4}$ of ordered mesoporous carbons. Black solid curves: fresh electrodes. Red dashed curves: after potential holding at $1.4 \mathrm{~V}$ vs. RHE.

Figure 5. Bode plots showing (a) impedance modulus (Z) and (b) phase angle, in $0.5 \mathrm{M}$ $\mathrm{H}_{2} \mathrm{SO}_{4}$ of ordered mesoporous carbons. Black curves: fresh electrodes. Red curves: after potential holding at $1.4 \mathrm{~V}$ vs. RHE.

Figure 6. Atomic ratio between different oxygen and carbon species according to XPS analysis to the electrodes. CA denotes after chronoamperometric tests. 
Figure 1
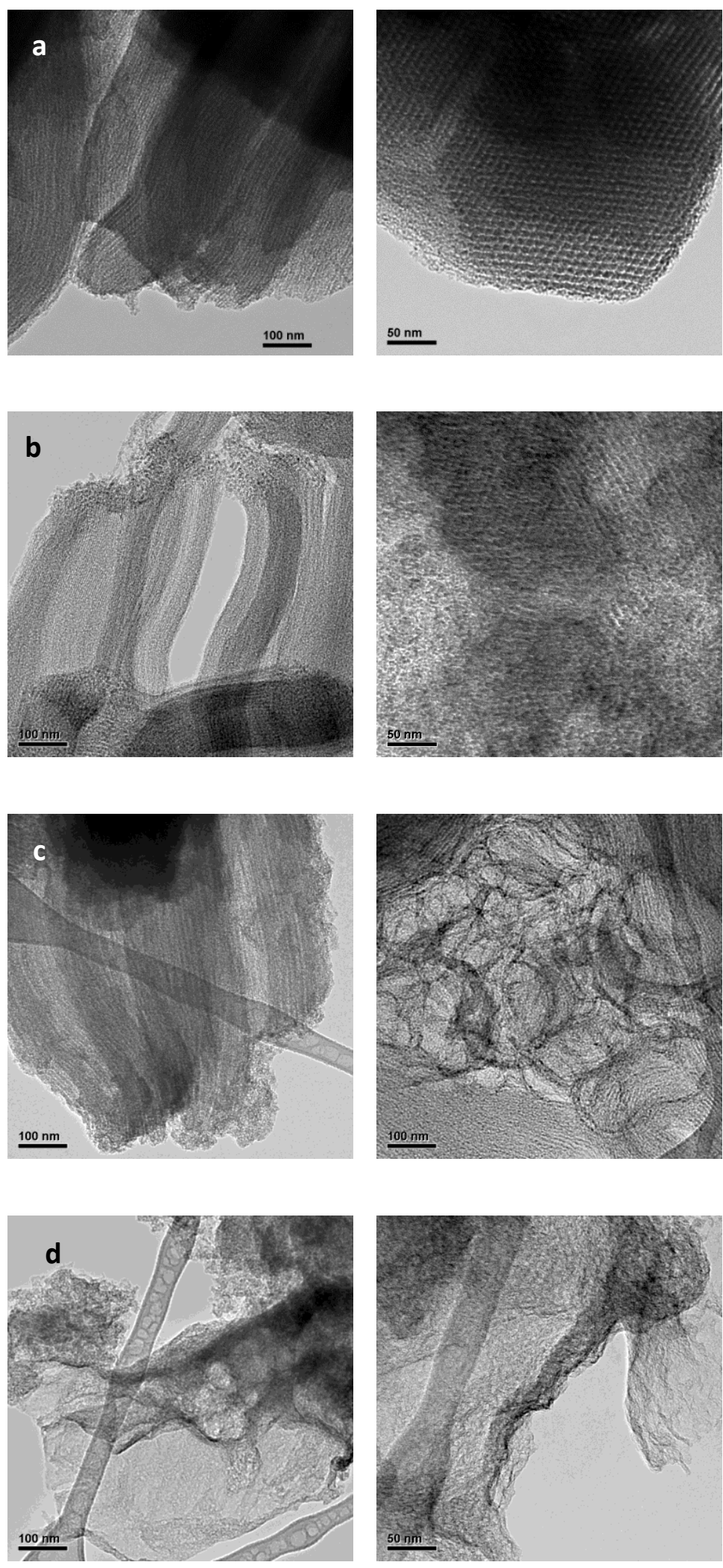
Figure 2
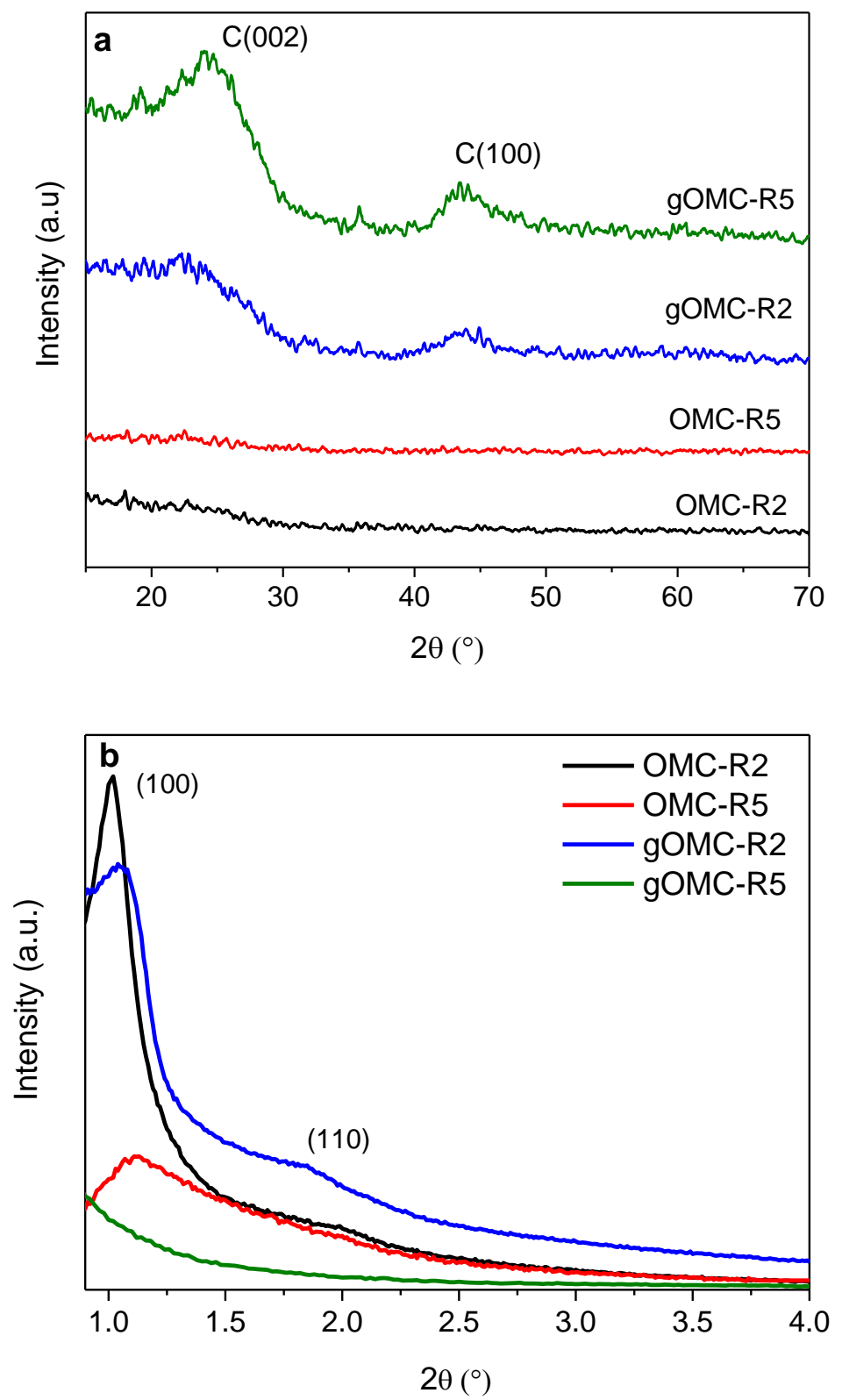
Figure 3

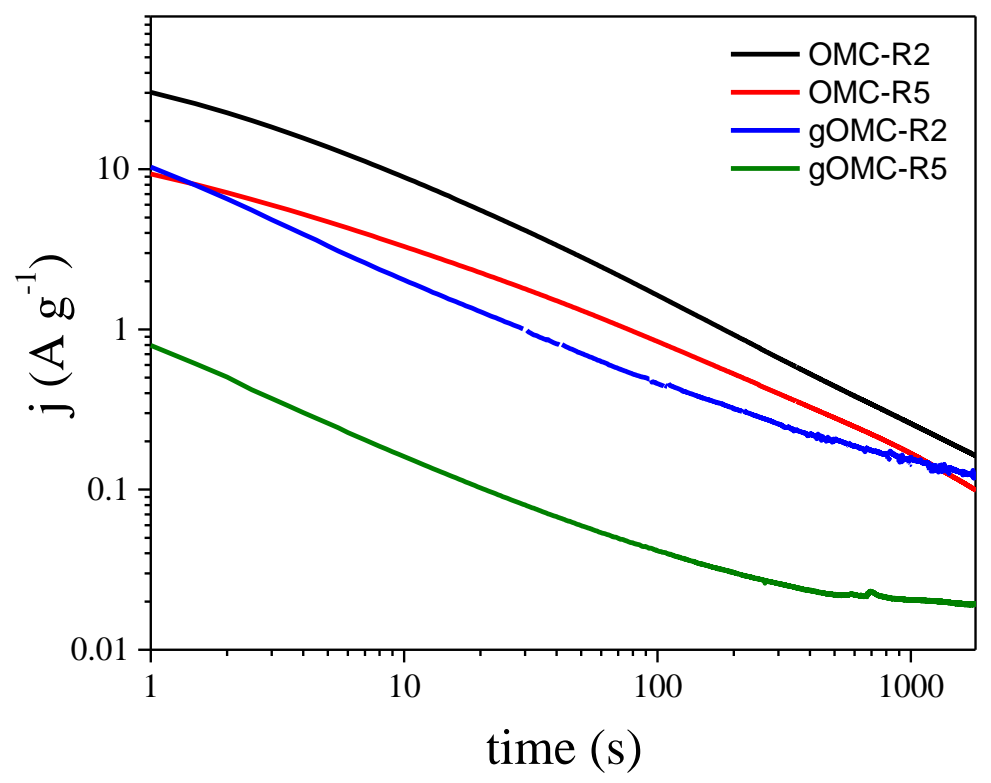


Figure 4
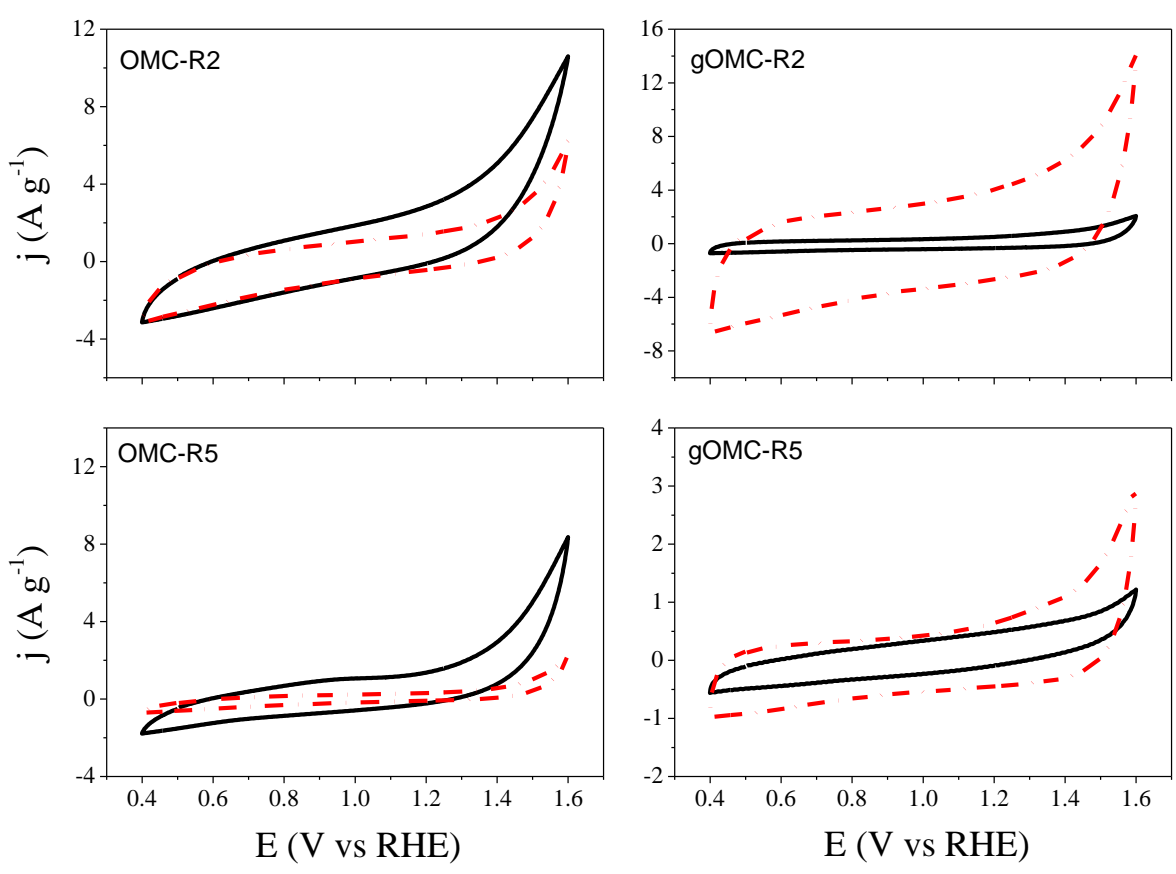


\section{Figure 5}
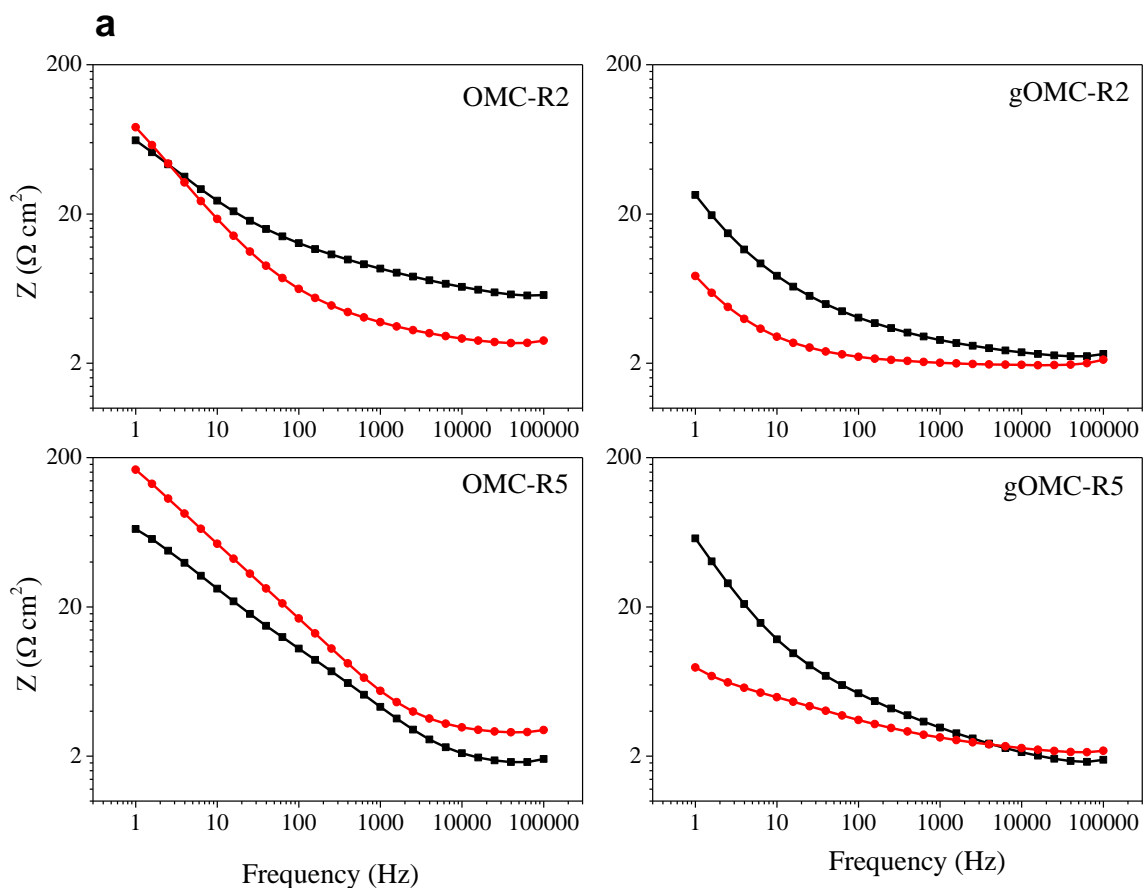

b
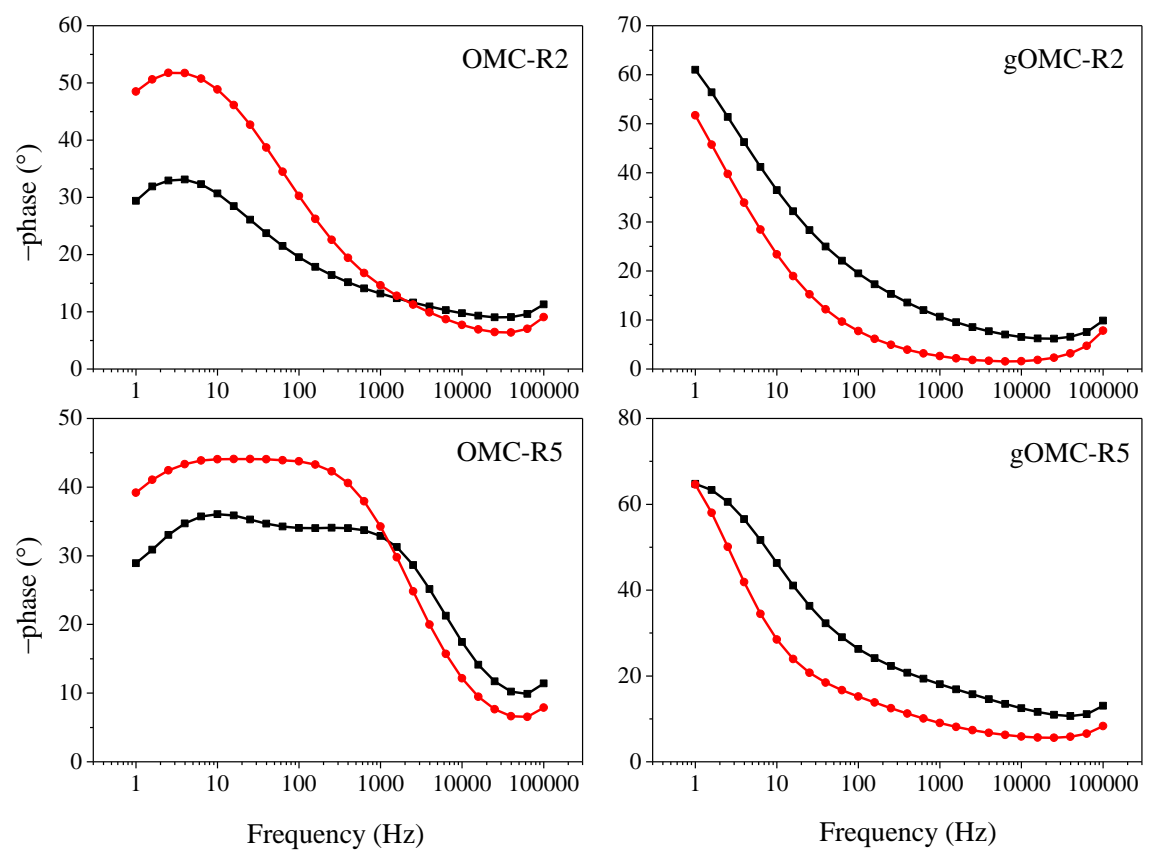
Figure 6

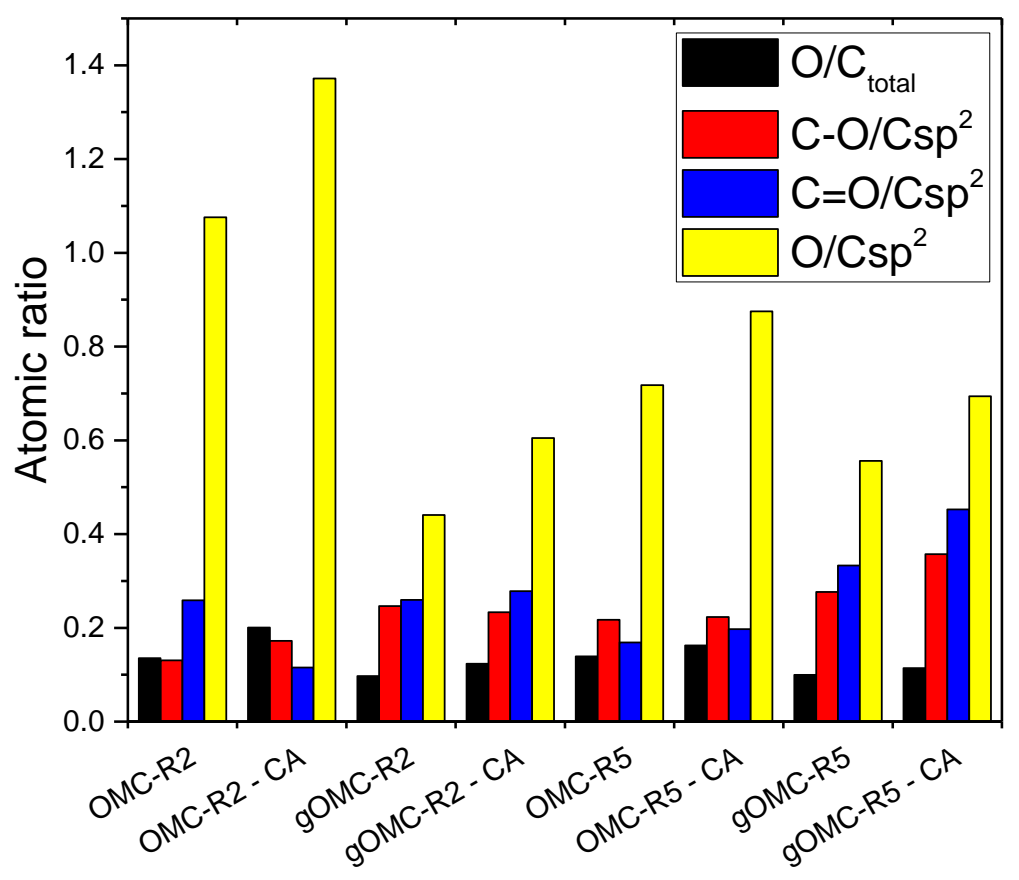

